\title{
Dielectric and Optical Band Gap Studies of Nanostructured Manganese Nickel Oxide and Cobalt Nickel Oxide
}

\author{
C R INDULAL ${ }^{1 *}, \mathrm{R}$ BIJU², \\ DEEPAK NAND ${ }^{2}$ and R RAVEENDRAN ${ }^{2}$
}

1Department of Physics, S.G. College, Kottarakara, Kerala, India. ${ }^{2}$ Nanoscience Research laboratory, S.N. College, Kollam, Kerala, India.

${ }^{\star}$ Corresponding author E-mail: Itdrindulal @gmail.com

http://dx.doi.org/10.13005/ojc/330365

(Received: April 08, 2017; Accepted: May 06, 2017)

\begin{abstract}
Nano oxides of Manganese Nickel and Cobalt Nickel were synthesized by chemical coprecipitation method from the reaction of respective metal sulfides of manganese, nickel, cobalt and sodium carbonate using ethylene diamene tetra acetic acid as an effective capping agent. The carbonate precursors were heated at different temperatures so as to form their oxides. Through the $\mathrm{X}$-ray line broadening technique, the mean particle sizes were calculated at different temperatures. The elastic micro strains versus particle size variations were thoroughly studied. The metal oxide formations of Manganese Nickel and Cobalt Nickel were confirmed with the help of FTIR spectra. EDX spectra of Manganese Nickel oxide and Cobalt Nickel oxide provide chemical composition of the samples. The crystallite shapes were studied using the scanning electron microscopy images. The optical direct band gap values of both Manganese Nickel and Cobalt Nickel oxides were calculated using Tauc's relation.
\end{abstract}

Keywords: Nanoparticles, SEM, EDX, Optical band gap, Dielectric properties

\section{INTRODUCTION}

Oxides of cobalt are stable and are available in abundance which are cheaper than other noble metals. In the recent past, oxide nanomaterials have been drawing wide attention due to their comparatively excellent electrical, optical ${ }^{1-2}$ or magnetic ${ }^{3}$ properties. Generally nanoparticles have large surface to volume ratio. So their properties such as electrical, optical, etc. can be tuned by engineering size, morphology or composition. Nano oxides of Manganese Nickel and Cobalt Nickel with large surface area can be used in gas sensors. These nano oxide systems may have entirely different properties compared to their parent bulk materials ${ }^{4}$. The ultra fine oxide nanoparticles exhibit unique UV absorbing ability, excellent stability at elevated temperatures, very high hardness and reactivity as catalyst $^{5-6}$. Manganese-Nickel oxide and CobaltNickel oxide systems can be considered as potential candidates for electrodes in batteries, in super capacitor, in sensors, switches etc. 


\section{MATERIALS AND METHODS}

The nano particles of both ManganeseNickel oxide $(\mathrm{MnNiO})$ and Cobalt-Nickel oxide (CoNiO) were synthesized by arrested precipitation from $\mathrm{AR}$ grade $0.4 \mathrm{M}$ cobalt sulphate, $0.4 \mathrm{M}$ nickel sulphate, $0.4 \mathrm{M}$ manganese sulphate and $0.6 \mathrm{M}$ sodium carbonate using ethylene diamene tetra acetic acid as an effective capping agent. The carbonate precipitates so formed were separated from the reaction combination and were washed with distilled water and ethanol to remove all impurities. The dried precipitates at room temperature were thoroughly grounded using an agate mortar to obtain their metal carbonate precursor in the form of fine powder. On heating to sufficient temperatures $\left(400,600\right.$ and $\left.800^{\circ} \mathrm{C}\right)$, these carbonate precursor decomposes to their corresponding metal oxides.

\section{Characterization}

$\mathrm{XRD}$ is one of the ideal techniques used for the determination of crystallite size of the nano powders. Based on the broadening of diffraction peaks, a few techniques involving Scherrer equation, Integral breadth analysis or Hall-Williamson approach and Fourier method of Warren-Averbach etc. were developed ${ }^{7-9}$. Warren and Averbach proposed the first theory related with the broadening of diffraction peaks. XRD studies were done on XPERT-PRO

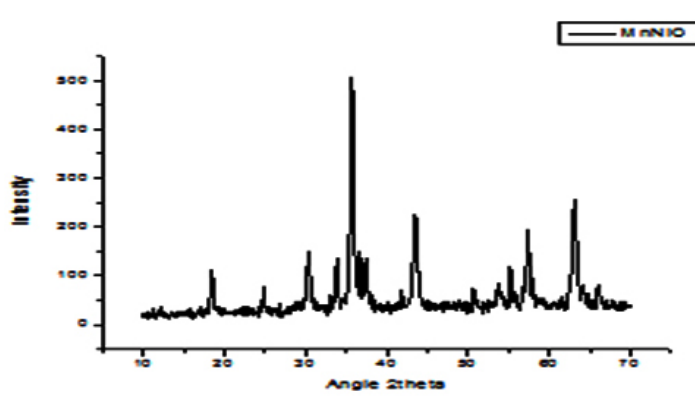

Fig. 1A: XRD pattern of $\mathrm{MnNiO}$ sintered at $600^{\circ} \mathrm{C}$

Table 1A

\begin{tabular}{lccc}
\hline Sintering & $\begin{array}{c}\text { Particle } \\
\text { temp }{ }^{\circ C}\end{array}$ & $\begin{array}{c}\text { Elastic } \\
\text { size }\end{array}$ (nm)strains & $\begin{array}{c}\text { Band } \\
\text { gap (eV) }\end{array}$ \\
\hline 400 & 8 & 0.002620 & 1.44 \\
600 & 17 & 0.001313 & 1.41 \\
800 & 41 & 0.000562 & 1.37 \\
\hline
\end{tabular}

powder diffractometer with $\mathrm{Cu}-\mathrm{K}_{\alpha}$ radiation in the $2 \theta$ range $10^{\circ}$ to $70^{\circ}$ at $30 \mathrm{~mA}, 40 \mathrm{kV}$. The surface morphological studies of the powder samples were evaluated by a scanning electron microscope. The energy dispersive analyses of $\mathrm{X}$ - rays were carried out on the nano samples to ascertain its precise composition. The ultra violet spectroscopic studies were carried out using Shimadzu UV-2550 UV visible spectrophotometer.

\section{RESULTS AND DISCUSSION}

\section{XRD Studies}

The nano crystallanity of the powder samples are verified using XRD analysis. The nano particle sizes are calculated using Debye-Scherrer equation, $d=0.9 \lambda / \beta \operatorname{Cos} \theta^{10}$, where $\beta$ represents the full width at half maximum of XRD lines, $\lambda=1.54060$ $[\AA]$. Figure $1 \mathrm{~A}$ and $1 \mathrm{~B}$ represents the $\mathrm{XRD}$ patterns of $\mathrm{MnNiO}$ and $\mathrm{CoNiO}$ sintered at $600^{\circ} \mathrm{C}$. The most intense peaks are obtained from the (311) planes. The crystallite sizes of $\mathrm{MnNiO}$ and $\mathrm{CoNiO}$ at 400 , 600 and $800{ }^{\circ} \mathrm{C}$ using Debye-Scherrer equation are as recorded in Table 1A and 1B respectively. On analyzing the table, it is confirmed that when the temperature increases, the particle size also increases. So temperature of the reaction can be considered as one of the prime parameters on the crystallites size ${ }^{11}$. The reason for increasing

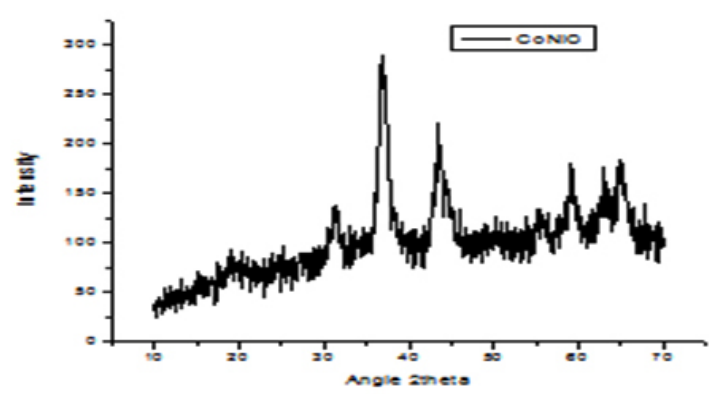

Fig. 1B: XRD pattern of CoNiO sintered at $600^{\circ} \mathrm{C}$

Table 1B

\begin{tabular}{lrrr}
\hline $\begin{array}{l}\text { Sintering } \\
\text { temp } \text { } C\end{array}$ & $\begin{array}{r}\text { Grain size } \\
(\mathbf{n m})\end{array}$ & $\begin{array}{r}\text { Elastic } \\
\text { strains }\end{array}$ & $\begin{array}{r}\text { Band } \\
\text { gap (eV) }\end{array}$ \\
\hline 400 & 6 & 0.003820 & 1.43 \\
600 & 20 & 0.001159 & 1.39 \\
800 & 42 & 0.000689 & 1.33 \\
\hline
\end{tabular}


particle size with increase in sintering temperature is either due to the Ostwald ripening or oriented attachment. Ostwald ripening happens mainly because, larger particles are energetically more

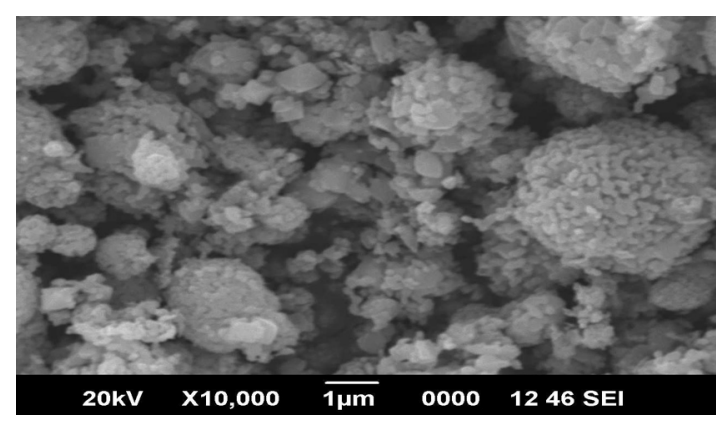

Fig. 2A: SEM image of $\mathrm{MnNiO}$ stable than smaller ones and it is also due to the effect of potential energy difference between larger and smaller particles which may happens through solid state diffusion. The crystallographic phases

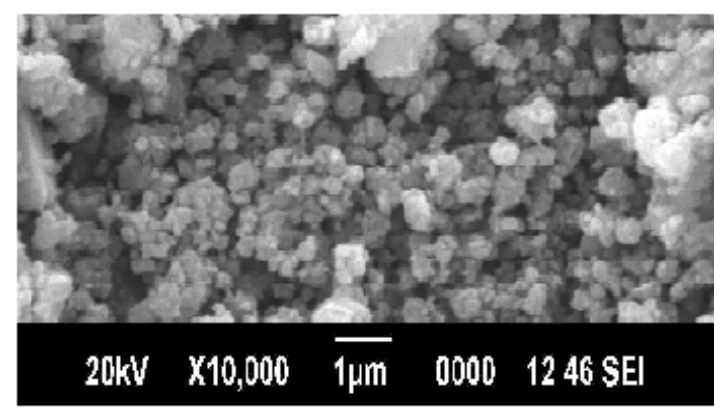

Fig. 2B: SEM image of CoNiO



Fig. 3A: EDX spectrum of MnNiO

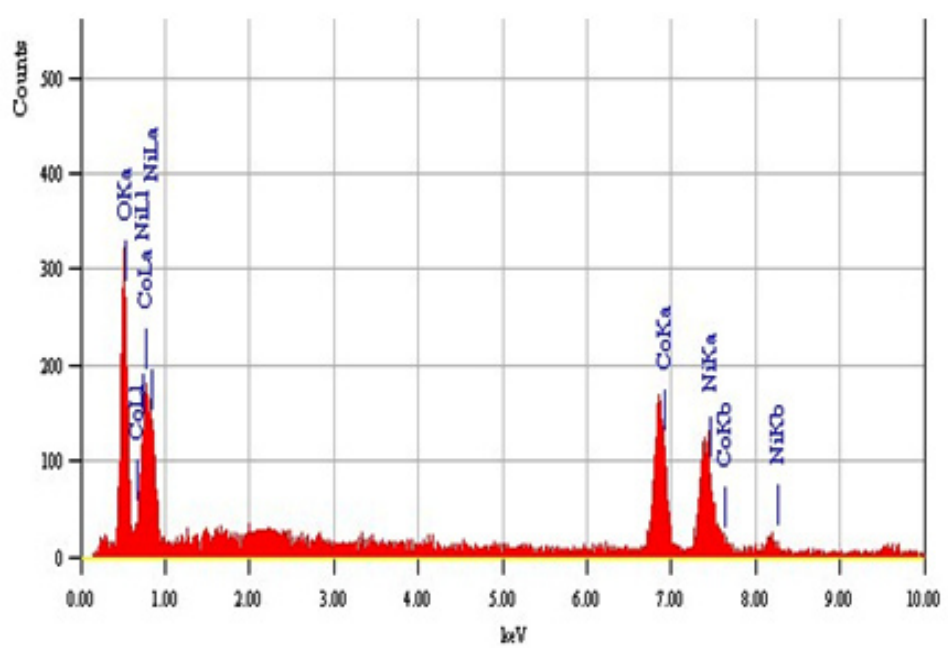

Fig. 3B: EDX spectrum of CoNiO 
and cubic structure of the synthesized nano particles are confirmed by comparing it with JCPDS files (File No 01-1110 and 20-0781). The basic reason for the broadening of the peaks in the XRD pattern is micro straining of the crystal structures which are arising from the various defects like dislocations/ twinning. They are supposed to be connected with chemically synthesized nanoparticles. At the time of crystals growth, the ligand may get only negligible time to diffuse to an energetically positive site which results in crystal defects ${ }^{12}$.

The elastic strain of $\mathrm{MnNiO}$ and $\mathrm{CoNiO}$ are found out using the values of full width at half maximum of $X R D$ lines ${ }^{13}$. From the table $1 \mathrm{~A}$ and $1 \mathrm{~B}$, it is confirmed that, as the nano particle size increases elastic strain decreases. This strain is one of the major reasons behind the broadening of the $\mathrm{XRD}$ peak of the nanomaterials.

\section{Microstructural studies}

For the surface morphological studies, the nano powders heated at $600 \stackrel{\circ}{\mathrm{C}}$ were transferred in to the SEM chamber. SEM images along with EDX of both $\mathrm{MnNiO}$ and $\mathrm{CoNiO}$ nanoparticles are shown in the Fig. 2A, 2B, 3A and $3 \mathrm{~B}$ respectively. The nanoparticles are found to be almost spherical with some agglomerations.

\section{FTIR Studies}

The FTIR spectra of both $\mathrm{MnNiO}$ and CoNiO are shown in Fig. $4 \mathrm{~A}$ and $4 \mathrm{~B}$ respectively. The absorption bands found in the regions $3420 \mathrm{~cm}^{-1}$ for $\mathrm{MnNiO}$ and $3430 \mathrm{~cm}^{-1}$ for $\mathrm{CoNiO}$ are

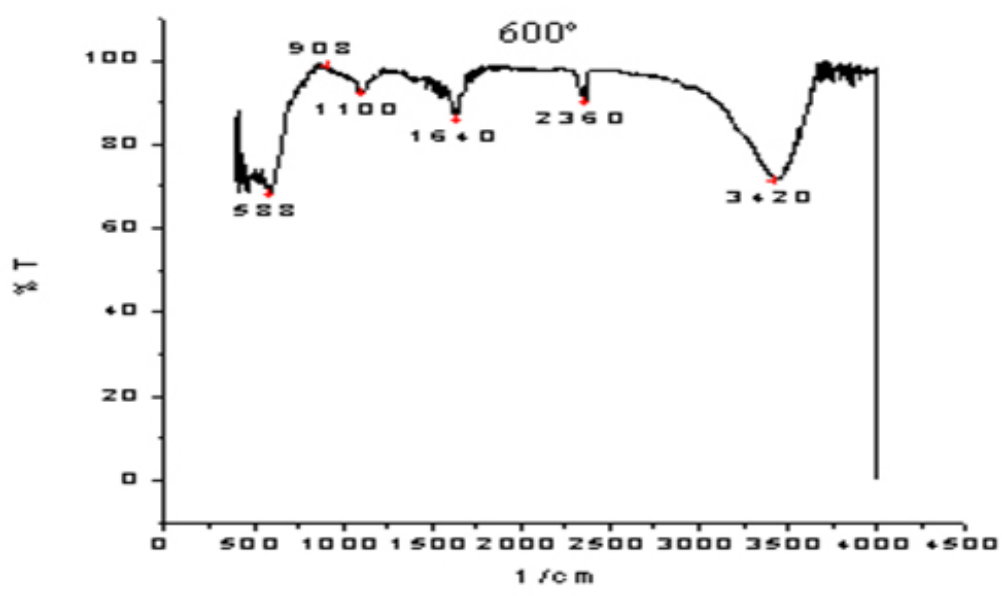

Fig. 4A: FTIR spectrum of MnNiO

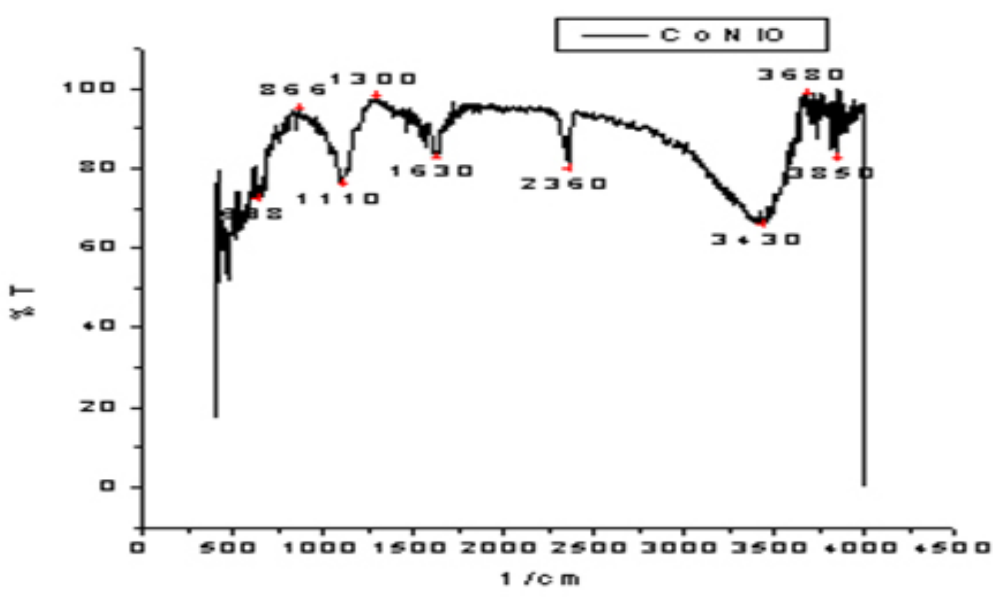

Fig. 4B: FTIR spectrum of CoNiO 
broad and are due to the presence of co-ordinated or entrapped water in the samples. The bands in the regions 1640 and $1630 \mathrm{~cm}^{-1}$ for both $\mathrm{MnNiO}$ and CoNiO correspond to carboxylate ions ${ }^{14-15}$. There are some bands around $600 \mathrm{~cm}^{-1}$ which might be due to the bending modes of the metal oxides in the nanoparticles.

\section{UV spectral studies}

The ultra violet spectra of both $\mathrm{MnNiO}$ and CoNiO sintered at 400,600 and $800{ }^{\circ} \mathrm{C}$ are taken in the wavelength range 200 to $800 \mathrm{~nm}$ are shown in fig $5 \mathrm{~A}$ and $5 \mathrm{~B}$ respectively. The optical band gaps of the nanoparticles are found out using the UV spectra.

On analyzing the UV spectra, there is a decrease in absorbance with increase in wavelength which can be considered as an indication of the presence of optical band gaps in the materials. This decrease corresponds to excitation of surface plasmons in the nano composite. The Tauc's relation connects energy band of the material and the absorption coefficient by the formula $\alpha h v=A(h v-E g)^{n}$, where $A$ is a constant, hv is the photon energy, $\mathrm{Eg}$ is the band gap energy; for an allowed direct transition the value of $n$ is $1 / 2$. $(\alpha h v)^{2}$ versus hv graphs in Fig 6A and 6B gives the of direct band gap values ${ }^{16}$ of $\mathrm{MnNiO}$ and $\mathrm{CoNiO}$ sintered at $600 \stackrel{\circ}{\circ}$.

When the sintering temperature increases, the nano particle size increases. However the band gap decreases. The reason for decreasing band gap with increase in sintering temperature may be due to the surface defects on the nanocomposite. So it is concluded that the band gap has an

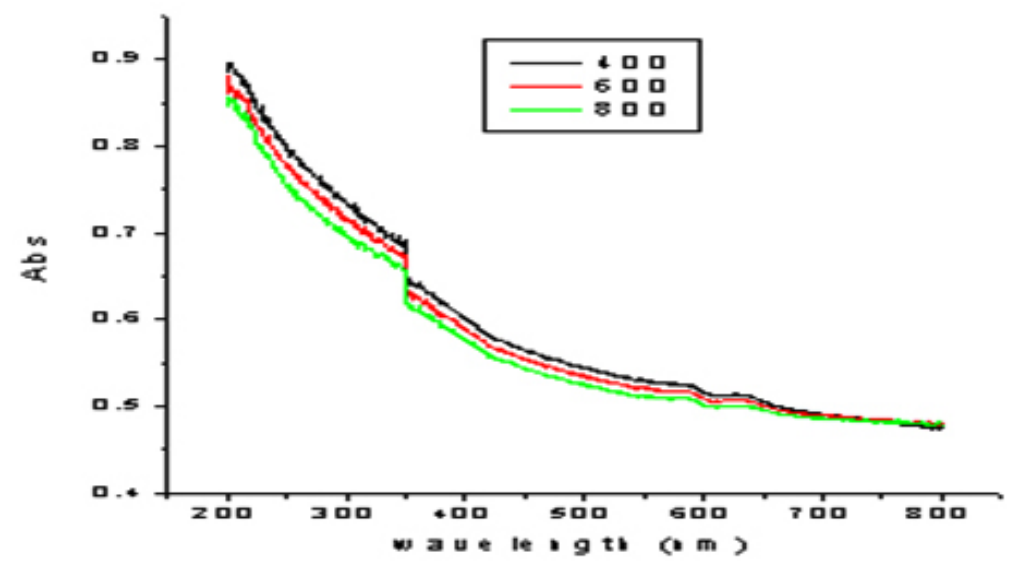

Fig. 5A: Absorbance versus wavelength graph for MnNiO sintered at different temperatures

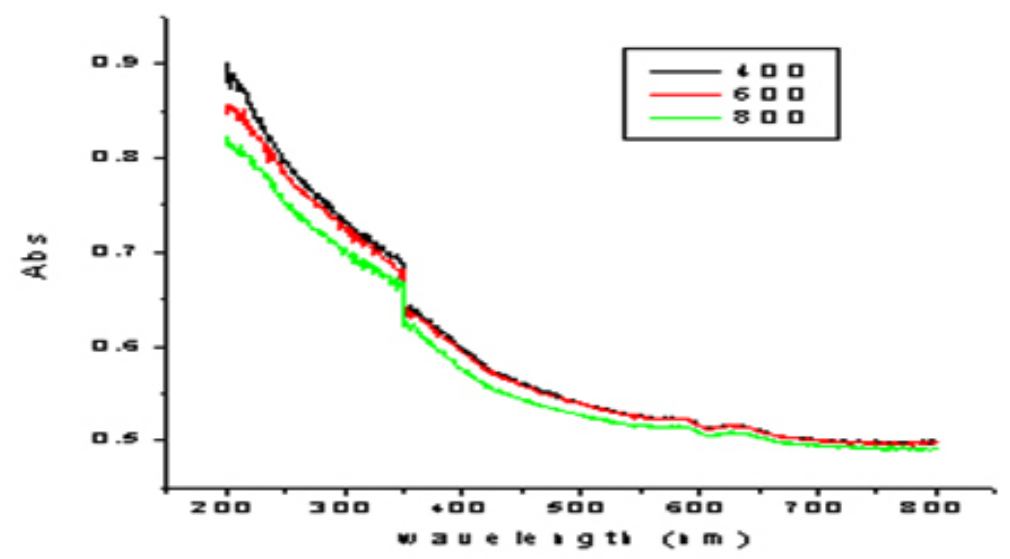

Fig. 5B: Absorbance versus wavelength graph for CoNiO sintered at different temperatures 




Fig. 6A: $(\alpha h v)^{2}$ vs hv graph for MnNiO sintered at $600{ }^{\circ} \mathrm{C}$

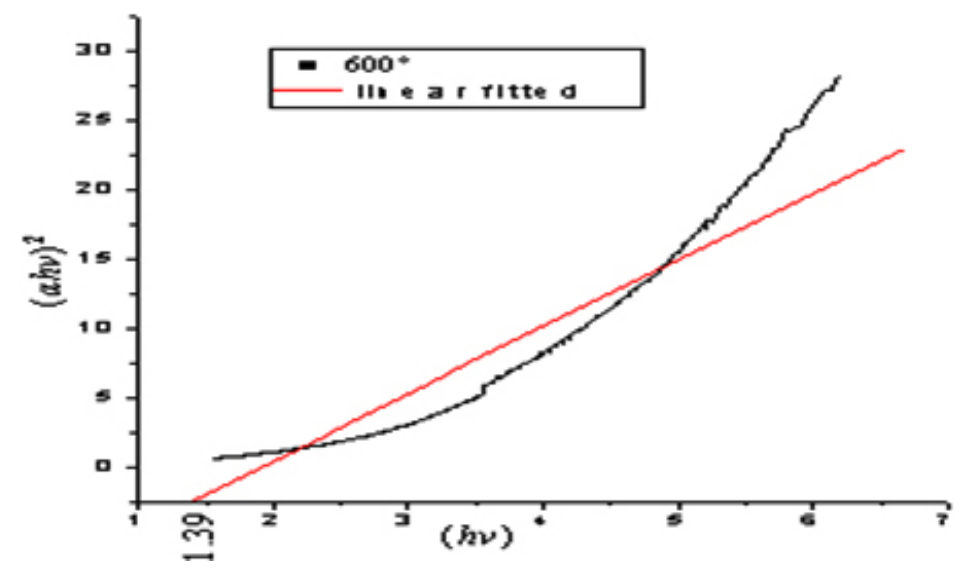

Fig. 6B: $(\alpha h v)^{2}$ vs hv graph for CoNiO sintered at 600 ㅇ

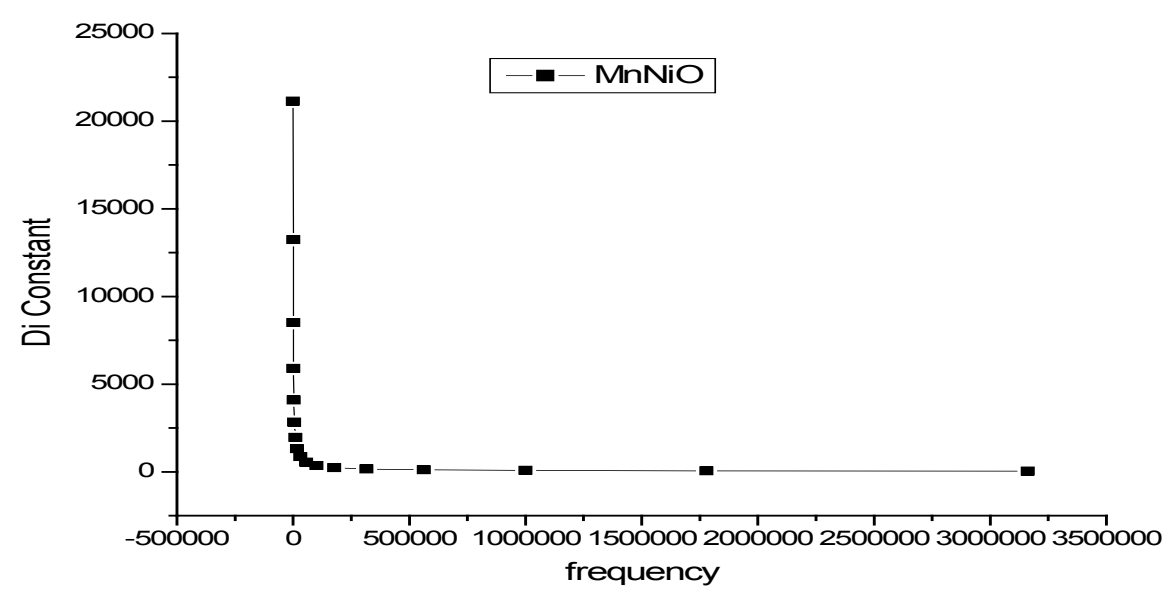

Fig. 7A: Dielectric constant-frequency graph of MnNiO at $600{ }^{\circ} \mathrm{C}$ 


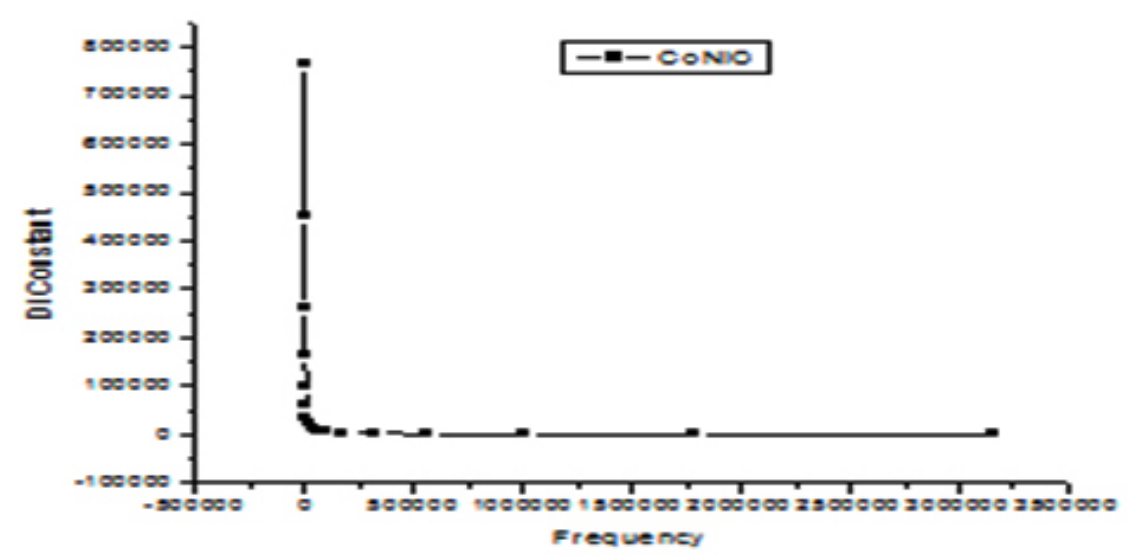

Fig. 7B: Dielectric constant-frequency graph of CoNiO at $600 \stackrel{\circ}{\circ}$

inverses dependence on the particle size of these nanocomposite.

\section{Dielectric studies}

To study the dielectric constant values of both $\mathrm{MnNiO}$ and $\mathrm{CoNiO}$, the nanopowders were first pelletized and then studied about the variations of dielectric constant with frequency of the applied field. Fig 7A and 7B represents the dielectric constant versus frequency graphs of both $\mathrm{MnNiO}$ and $\mathrm{CoNiO}$ at $600^{\circ} \mathrm{C}$. The dielectric constant decreases very fast in the low frequency region but after that it reaches a constant value which shows that it is independent of frequency at high frequency region. The dielectric nature of the nanoparticles is mainly due to space charge and rotational polarizations ${ }^{17}$. Nanoparticles possess a large number of interfaces and the defects in these interfaces can cause a change of positive as well as negative space charge distribution. In the presence of an electric field these space charges can move and may be trapped by the defects which results in the formation of dipole moments. Interfaces found in nanoparticles contain several oxygen ion vacancies, and are equivalent to positive charges giving dipole moments. When exposed to an electric field, these dipoles can rotate, giving a resultant dipole moment in the direction of the field. These are the reasons for the high value of dielectric constant at low frequencies ${ }^{18}$.

CoNiO nanoparticles are found to be better dielectric material than $\mathrm{MnNiO}$ nanoparticles at all frequencies especially in the lower regime.

\section{CONCLUSIONS}

Nanoparticles of Manganese-Nickel Oxide and Cobalt-Nickel oxide were prepared by arrested precipitation. The X-ray diffractograms compared with JCPDS data confirms the presence of the cubic phases with prominent peaks at (311). From the XRD analysis, there is a direct dependence of sintering temperature and particle size. The nanoparticles are found to be almost spherical in shape with agglomerations to a certain extend. Optical absorption studies indicate that ManganeseNickel Oxide and Cobalt-Nickel oxides have the direct band gaps which decrease with increase in temperatures. Variations in the dielectric constant with frequency of the applied field are thoroughly studied for both the samples so as to recommend CoNiO as a better dielectric material compared to $\mathrm{MnNiO}$ nanoparticles.

\section{REFERENCES}

1. Lopez, R.; Haynes, T .E.; Boatner, L. A.; Haglund, R. F.; Opt. Lett. 2002, 27, 13271329.

2. Ikeyama, M.; Nakao, S.; Tazawa, M.; Kamada,
K.; Nucl Instrum Methods Phys. Res. B 2001, 652, 175-177.

3. Muroi, M.; Street, R.; McCormick, P. G.; J. Appl. Phys. 2000, 87, 3242-3244. 
4. Kenneth J. Klabunde; Cathymohs, Department of Chemistry, Kansas state university, Manhanttan Kansas second Edition, 1998.

5. Tsai, M. S.; Mater. Sci. Eng. B. 2004, 110, 132-134.

6. Mori, Wang, Y. R.; Drennan, Solid State lonics 2004, 175, 641-649.

7. Scherrer, P.;, Math. Phys. K. 1918, 1, 187.

8. Williamson, G. K.; Hall, W. H.; Acta Metall. 1953, 1, 22-31.

9. Warren, B. E.; Averbach, B. L.; J. Appl. Phys. 1950, 21, 595-599.

10. Cullity, B. D.; Elements of X-ray diffraction, Addison - wesley publishing company Inc California, 1970 . 102.

11. Wang, L. P.; Hong, G. Y.; Qu, S. C.; Wang, Z. G.; Nanotechnology. 2005, 16, 1469-1473.
12. Warad, H. C.; Ghosh, S. C.; Hemtanon; Sci. Technol. Adv. Mater. 2005, 6, 296-301.

13. Robert Kelsall; Ian Hamley; Mark Geoghegan; Nano Scale Science \& technology, (John Wiley, Chichester), 2005.

14. Ehrlich, G.; J Am Chem Soc. 1954, 76, 52635268.

15. Douville, F.; Duval, G.; Lecomte, J.; Compt Rend Acad Sci. 1941, 963, 212.

16. Mohanta, D.; Nath, S. S.; Mishra, N. C.; Choudhury, A.; Bull. Mater. Sci. 2003, 26, 289-294.

17. Mo Chi-Mel; Zhang Lide; Wang Guozhong, Nanostuctr Mater. 1995,6, 823-826.

18. Tareev, B.; Physics of dielectric materials (Mir Publishers, Moscow), 1979. 